Check for updates

Cite this: RSC Adv., 2018, 8, 278

Received 5th November 2017

Accepted 8th December 2017

DOI: $10.1039 / c 7 r a 12148 b$

rsc.li/rsc-advances

\section{Bacteria killing in ICU associated infections: antibacterial nanosheets as disinfectant $\dagger$}

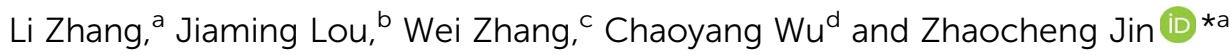

\section{Introduction}

Disinfectant agents are essential components in the practice of control and prevention of bacterial infections, especially in intensive care units (ICUs), where there have been extensive reports on multidrug resistant bacteria such as carbapenemresistant acinetobacter baumannii, methicillin resistant S. aureus (MRSA) and multidrug resistant (MDR) E. coli, etc. ${ }^{1 a}$ Traditionally, iodophor and hydrogen peroxide $\left(\mathrm{H}_{2} \mathrm{O}_{2}\right)$ were widely used as ICU disinfectant due to their strong oxidizing abilities to cause the denaturing of bacteria and consequently bacterial progressive lysis. ${ }^{1 b, c}$ Given the fact that ICU associated bacteria could develop mutations to covert to multi-drug resistance, Kempf et al., demonstrated that iodophor and $\mathrm{H}_{2} \mathrm{O}_{2}$ resistant microorganism emerged recently, and these multidrug resistant bacteria were growing more invulnerable. ${ }^{1 d}$

\footnotetext{
${ }^{a}$ Department of Critical Care Medicine Unit, The Affiliated People's Hospital of Jiangsu University, Zhenjiang, Jiangsu, China. E-mail:JinZhaoC@163.com

${ }^{b}$ Department of Emergency Medicine, The Affiliated People's Hospital of Jiangsu University, Zhenjiang, Jiangsu, China

'Department of Pain Medicine, The Affiliated People's Hospital of Jiangsu University, Zhenjiang, Jiangsu, China

${ }^{d}$ Department of Oncology, The Affiliated People's Hospital of Jiangsu University, Zhenjiang, Jiangsu, China
}

$\dagger$ Electronic supplementary information (ESI) available. See DOI: $10.1039 / \mathrm{c} 7 \mathrm{ra} 12148 \mathrm{~b}$
Additionally, Campos et al., have recently found that bacteria (e.g., MRSA) was resistant against a variety of other candidate disinfectants including sodium hypochlorite, glutaraldehyde, formaldehyde, ethanol, chlorhexidine gluconate, and quaternary ammonium. ${ }^{1 e} \mathrm{~A}$ practical method to combat against bacterial resistance is thus urgently to be developed.

The application of nanomaterials into bacterial killing is a promising alternative solution, since these nanoparticles have been proven to be highly reactive in antibiosis compared with those chemical compounds. ${ }^{2 a, b}$ Several mechanisms, including reactive oxygen species (ROS), metal ion leaking, electrostatic interactions and structural associated physical damage, ${ }^{2 c, d}$ are proposed to contribute to their antibacterial behaviours. Among them, physical damage to bacteria is irreversible, and this class of materials emerges as ideal candidates for the development of disinfectants. One of the promising nanomaterials is graphene oxide (GO), a strongly oxygenated and highly hydrophilic two dimensional (2D) layered material with biocompatibility, large specific surface area, high chemical and thermal stability, ${ }^{3 a-c}$ and most importantly, bacterial killing abilities. Fan et al., have recently introduced a GO based antibacterial paper which exhibited minimal cytotoxicity to mammalian cells, but effective towards bacterial inhibition. ${ }^{3 d}$ Elimelech et al., further demonstrated that GO might cause bacterial lysis by means of their sharpened edges and elevated membrane pressure. ${ }^{3 e}$ Similarly, Ivanova et al., proposed that GO inactivated 
microorganism through the density and orientation of their graphene edges, which led to pore forming in bacterial membrane. ${ }^{3 f}$ Despite these recent achievements, GO itself, however, was rarely evaluated against multi-drug resistant bacteria, such as multidrug resistant (MDR) E. coli, methicillin resistant $S$. aureus (MRSA). ${ }^{4 a-c}$ Moreover, GO were typically evaluated on assembled GO integrity, including GO paper $^{3 e}$ and GO membrane, ${ }^{3 f}$ while antibacterial effect from individually dispersed GO nanosheet was unsatisfying. ${ }^{3 c}$ Strategy to decorate GO nanosheets with structure-featured metal oxides that share the physical damage towards bacteria was recently proposed to address this issue, as it not only took advantage of the large specific surface area and morphological features from GO, but also introduced the bacterial activities of metal oxides simultaneously. ${ }^{4 d-f, 5}$

Previously, Wu et al., have proposed a Zn-CuO@GO decorated commercial porous nickel (Ni) electrode and demonstrated its ability for efficient capture, rapid killing and ultrasensitive detection of bacteria (normal bacterial stains such as E. coli (ATCC 25922) and S. aureus (ATCC 29213) was evaluated). ${ }^{6 a}$ Its behaviour upon contact with multi-drug resistant strains remained elusive, and despite of its effectivity, the electrode was not practical to apply into ICU-associated disinfectant due to its size $(6 \mathrm{~mm} \times 24 \mathrm{~mm})$. In contrast, we were able to synthesis $\mathrm{Zn}-\mathrm{CuO} @ G O$ nanosheets to apply as disinfectants and demonstrated their activities to combat against multi-drug resistant bacteria strains. Different from previous works, we obtained $\mathrm{Zn}-\mathrm{CuO} @ \mathrm{GO}$ nanosheet solely through in situ deposition and growth, and also, we prepared Zn-CuO@GO with different deposition ratios (i.e., $\mathrm{Zn}-\mathrm{CuO}: \mathrm{GO}=4: 1,2: 1$ and $1: 1, \mathrm{w} / \mathrm{w}$ ) where $\mathrm{Zn}-\mathrm{CuO}$ that possessed a prickly architecture was allowed to deposit and grow in situ onto GO nanosheets to obtain the hybrid antibacterial nanosheets. ${ }^{6 \boldsymbol{b}, \boldsymbol{c}}$ The $\mathrm{Zn}-$ CuO@GO suspensions were applied as a disinfectant. Taking multi-drug resistant E. coli (MDR E. coli) and a methicillin resistant $S$. aureus (MRSA) as examples, these antibacterial nanosheets could effectively inhibit bacterial growth via physical damage, which was confirmed through TEM and SEM. Results indicated that these hybrid nanosheets function as effective antibacterial agents to penetrate into the cellular wall and cause bacterial lysis upon contacting, which was largely due to the fact that they possessed the 'blades' from GO and 'pierces' from prickly $\mathrm{Zn}-\mathrm{CuO}$ simultaneously. ${ }^{7 \boldsymbol{a}}$ As these antibacterial nanosheets function to cause bacterial lysis through physical damage, possible genetic mutation and development of other drug resistant mechanism might not be applicable. ${ }^{7}$ To this end, antibacterial $\mathrm{Zn}-\mathrm{CuO} @ G O$ nanosheets is promising as an alternative disinfectant applied in ICU.

\section{Results and discussion}

By taking advantage of sonochemical method, we fabricated GO nanosheets packaged with prickly $\mathrm{Zn}-\mathrm{CuO}$. Briefly, the metal ions $\left(\mathrm{Cu}^{2+}\right.$ and $\left.\mathrm{Zn}^{2+}\right)$ were firstly allowed to chelate onto GO nanosheets, where ultrasmall nanoclusters were then deposited and readily grew in situ via sonochemical assisted green energies (Fig. 1A). ${ }^{7 a}$ As indicated in the transmission electron microscopy deposition

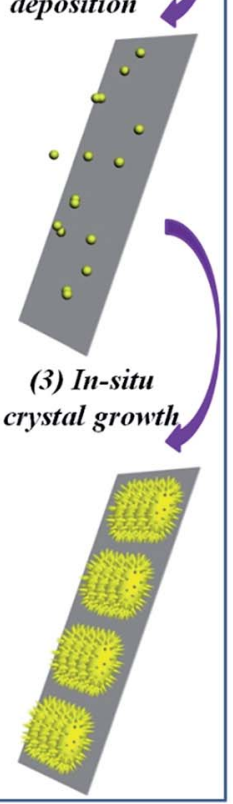

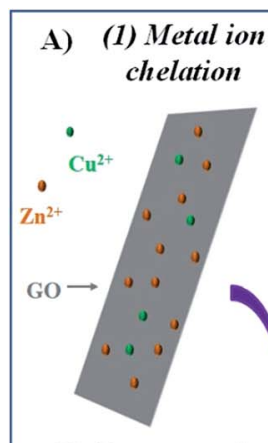

(2) Nanocrystal
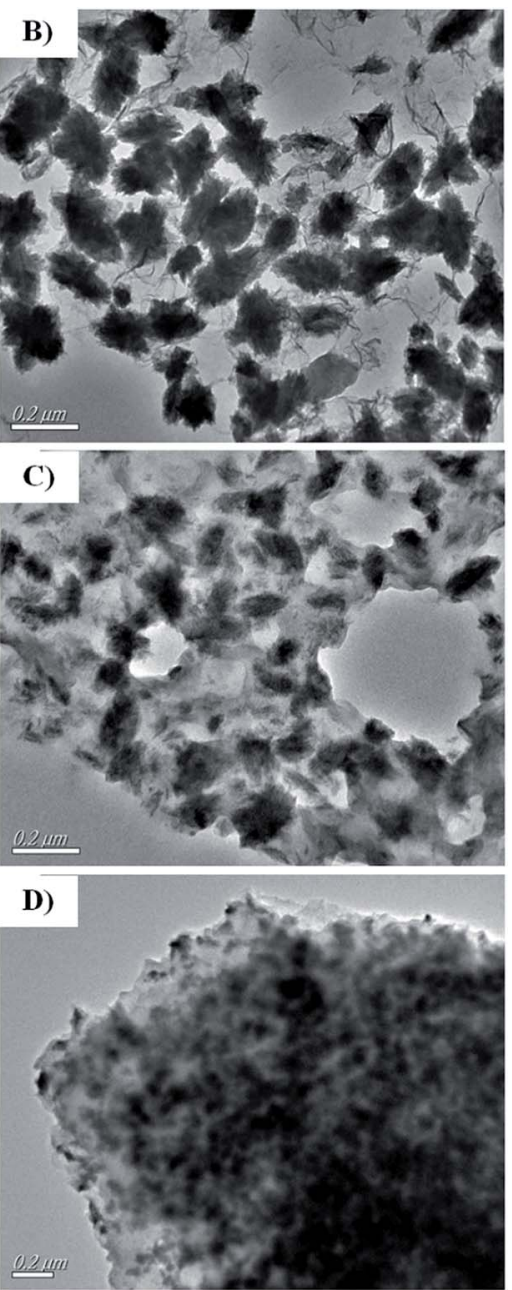

Fig. 1 (A) Schematic illustration of the formation of $\mathrm{Zn}-\mathrm{CuO}$ aGO from sonochemical method. TEM image of $Z n-C u O @ G O ~(4: 1)$ (B), $\mathrm{Zn-CuO@GO}(2: 1)(\mathrm{C})$, and Zn-CuO@GO (1:1) (D).

image (TEM, Fig. 1B), the prickly $\mathrm{Zn}-\mathrm{CuO}$ were randomly and successfully deposited onto individual GO nanosheets $(4: 1, \mathrm{w} /$ $\mathrm{w}$ ), which was similar to previous reports (specifically, the deposition weight ratio was calculated from ICP results (Table S1, ESI $\dagger$ )). The dark rugby-like shape and the sublayer sheet indicated for the prickly $\mathrm{Zn}-\mathrm{CuO}$ and GO, respectively. As indicated in Fig. 1B, the pricks from $\mathrm{Zn}-\mathrm{CuO}$ were well preserved, arising from their successful in situ nanocrystal deposition and nanoparticle growth. Different from previous works, we obtained Zn-CuO@GO solely from the sonochemical reactions other than scratched from the electrode, and prepared hybrid antibacterial nanosheet in other deposition ratios, i.e., $2: 1$ (Fig. 1C) and 1:1 (Fig. 1D) (w/w) for comparison. Compared with Zn-CuO@GO obtained at 4:1 (w/w), Zn-CuO@GO prepared at $2: 1$ and $1: 1(\mathrm{w} / \mathrm{w})$ were largely in agglomerate (Fig. 1C and D). It is possibly due to the comparably overabundance of GO nanosheets, as there exists strong $\pi-\pi$ stacking between GO nanosheets. Also, the zeta potential of the hybrid antibacterial nanosheet was measured in saline (ESI, Fig. S1 $\dagger$ ), which indicated that it was positively charged after $\mathrm{Zn}-$ $\mathrm{CuO}(\zeta>0)$ was deposited into GO nanosheets $(\zeta<0)$. 
As indicated in Fig. 2, compared with $\mathrm{Zn}-\mathrm{CuO}$ (Fig. 2a) and GO (Fig. 2b), the typical XRD peaks of the hybrid antibacterial nanosheet (Fig. 2c-e) exhibited similar pattern with pristine prickly $\mathrm{Zn}-\mathrm{CuO}$ at $2 \theta=32.47^{\circ}, 35.49^{\circ}, 38.68^{\circ}, 48.65^{\circ}, 58.25^{\circ}$, and $61.45^{\circ}$ (Fig. 2a-c), indicating the existence of $\mathrm{Zn}-\mathrm{CuO}$ in the GO layers. ${ }^{7 a}$ The reason why there were no obvious peaks from GO that may bear a typical peak at $12^{\circ}$ (Fig. 2b) was possibly due to the coverage of other strong peaks from $\mathrm{Zn}-\mathrm{CuO}$ NPs, which was also in consistence with previous reports. ${ }^{4 g}$ In synergistic with TEM images in Fig. 1B-D, the synthesis of $\mathrm{Zn}-\mathrm{CuO} @ G O$ was demonstrated successful.

Further, the biocidal activity of $\mathrm{Zn}-\mathrm{CuO} @ G O$ suspension based disinfectant was quantitatively evaluated against a multidrug resistant $E$. coli (MDR E. coli) and a methicillin resistant S. aureus (MRSA). ${ }^{7 a}$ Briefly, after treatment with $\mathrm{Zn}-\mathrm{CuO} @ \mathrm{GO}$ suspensions (at concentrations of $0.1 \mathrm{mg} \mathrm{mL}{ }^{-1}$ ), the viable bacteria were monitored by counting the number of colonyforming units (CFU) with respect to time. ${ }^{7 a}$ As presented in Fig. 3, representative results clearly indicated that $\mathrm{Zn}-\mathrm{CuO}$ @GO effectively inactivated those multi-drug resistant strains nearly completely after $10 \mathrm{~min}$ of treatment (yellow and green dashed lines), except for Zn-CuO@GO (1:1) (purple dashed lines). Compared with GO which exerted minimal cytotoxicity towards these bacterial strains even after over $3 \mathrm{~h}$ of treatment (blue bar), it could be concluded that after integrated with GO sheets, the deposited prickly $\mathrm{Zn}-\mathrm{CuO}$ could greatly enhance their combinational bacterial killing activity. ${ }^{4 f, 7 a}$ Notably, the antibacterial abilities of $\mathrm{Zn}-\mathrm{CuO} @ \mathrm{CuO}$ at different mass ratios were different, as Zn-CuO@GO (4:1) and Zn-CuO@GO (2:1) shared similarity in superiority in combating multi-drug resistant microbes, while Zn-CuO@GO (1:1) took more time ( $\sim 30 \mathrm{~min})$ for a complete bacterial inhibition. Based on a 10 min time scale after treatment, GO might account for a maximum $3.6 \%$ antibacterial activity while $\mathrm{Zn}-\mathrm{CuO}$ accounted for at least $96.4 \%$. Thus, we concluded that the deposition density of $\mathrm{Zn}-\mathrm{CuO}$ contributed significantly to the combinational antibacterial activities of $\mathrm{Zn}-\mathrm{CuO} @ G O$, and $\mathrm{Zn}$ CuO@GO (4:1) exhibited the best performance. Additionally, taking consideration of its flexible architecture and good

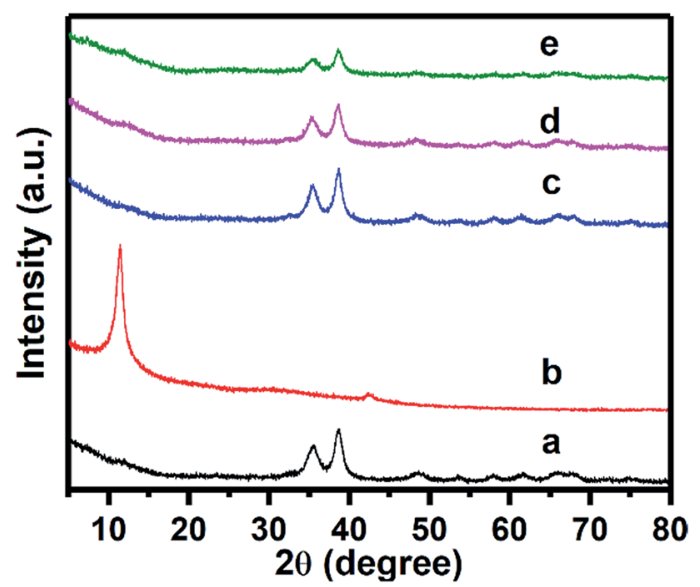

Fig. 2 XRD pattern of $\mathrm{Zn}-\mathrm{CuO}$ (a), GO (b), Zn-CuOaGO (4:1) (c), Zn-CuO@GO (2:1) (d), and Zn-CuO@GO (1:1) (e), respectively.
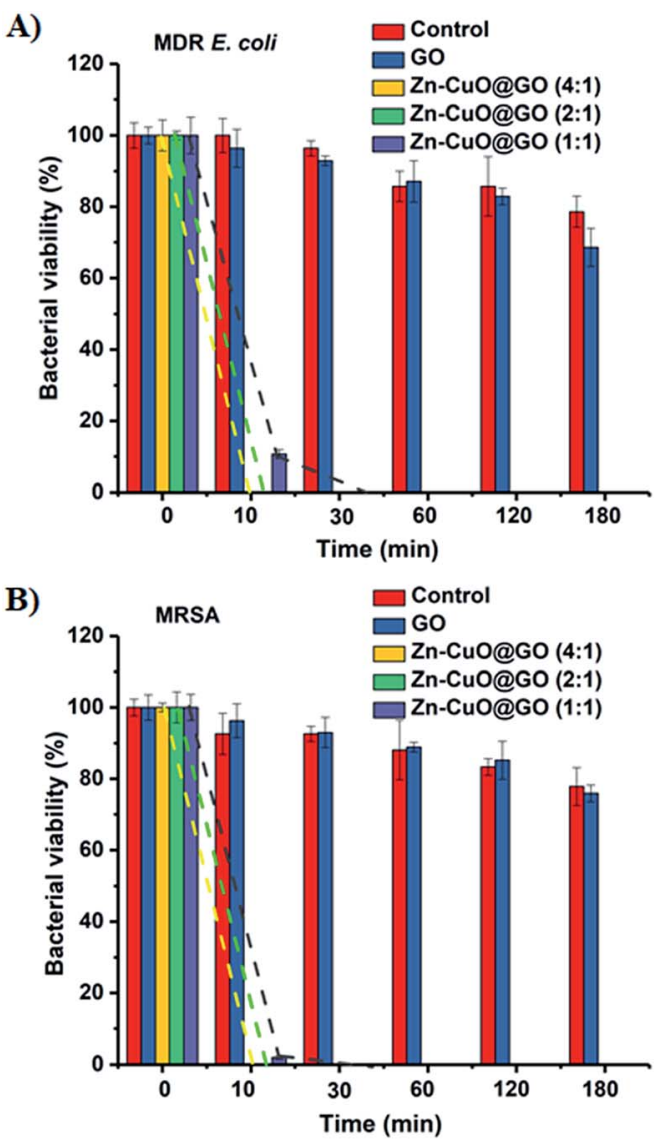

Fig. 3 Bacterial viability after treatment of GO, Zn-CuO@GO (4:1), $\mathrm{Zn}-\mathrm{CuOAGO}(2: 1)$, and $\mathrm{Zn}-\mathrm{CuO}$ aGo $(1: 1)$ at $0.1 \mathrm{mg} \mathrm{mL}{ }^{-1}$ for different time intervals, respectively. Results for MDR E. coli and MRSA were represented in ( $A$ and $B$ ), respectively.

dispersity, which introduced many possibilities for further

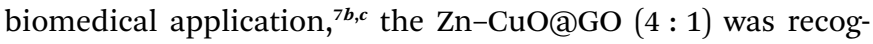
nized and chosen as the optimized composite for further evaluation. If not otherwise mentioned, the following $\mathrm{Zn}-\mathrm{CuO} @ \mathrm{GO}$ refers to Zn-CuO@GO (4:1). In comparison with selected works on similar materials (Table S2, ESI $\dagger$ ), it was suggested Zn-CuO@GO actively inhibited multi-drug resistant bacteria stains almost completely within $10 \mathrm{~min}$, which rendered themselves promising candidates as a ICU applicable disinfectant.

Live/dead dual-staining was conducted to investigate the bacterial viability after exposure to $\mathrm{Zn}-\mathrm{CuO} @ G O$, and bacterial without any treatment was chosen as control (Fig. 4). ${ }^{4 a, 7 c}$ PI was used specifically to stain membrane perturbed cell with red fluorescence and DAPI was used to label all bacterial nucleus with blue fluorescence. $\mathrm{Zn}-\mathrm{CuO} @ \mathrm{GO}$ was also pre-stained with FITC, a green fluorescence utilized widely, to indicate its existence. Notably, bacteria were stained with PI before fixation to indicate the ratio of dead bacteria. It was found that there was scarcely red fluorescence detected for both MDR E. coli and MRSA without treatment, which was in consistence with previous reports. After treated with $\mathrm{Zn}-\mathrm{CuO} @ \mathrm{GO}$ at $0.1 \mathrm{mg} \mathrm{mL} \mathrm{mL}^{-1}$, however, it was found that there were severe aggregations 


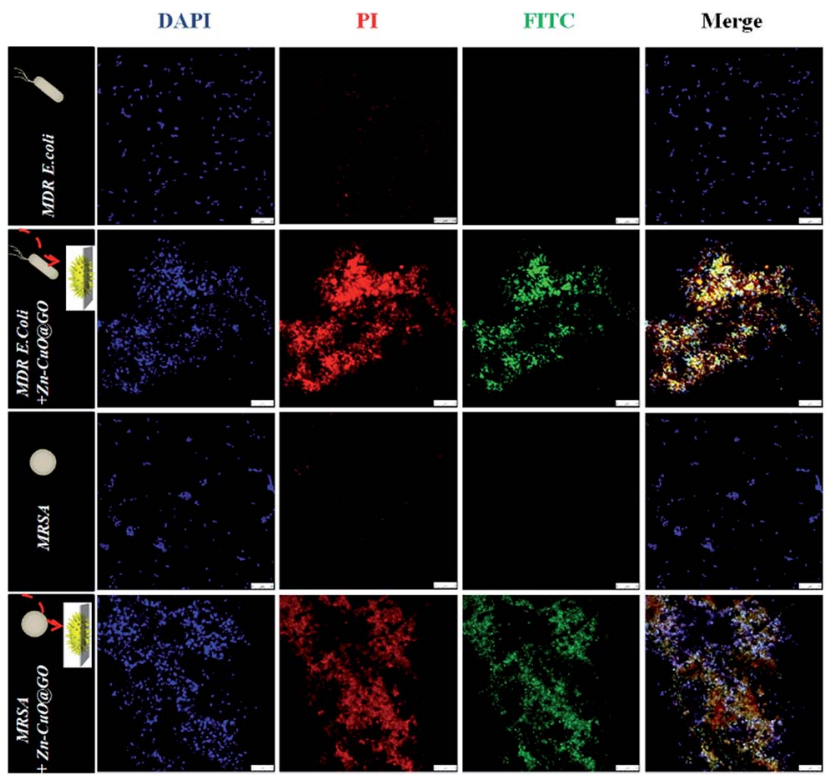

Fig. 4 The laser confocal scanning microscope images of MDR E. coli and MRSA before and after 30 min treatment with $\mathrm{Zn}-\mathrm{CuO}$ aGO nanosheets. The concentrations of $\mathrm{Zn}-\mathrm{CuO}$ @GO were fixed at $0.1 \mathrm{mg} \mathrm{mL}^{-1}$ in $0.9 \%$ of $\mathrm{NaCl}$ aqueous solution. DAPI (blue fluorescence), PI (red fluorescence), and FITC (green fluorescence) were used to stain total bacteria, dead bacteria, and the $\mathrm{Zn}-\mathrm{CuO}$ aGO composite, respectively. Scale bar is $10 \mu \mathrm{m}$.

observed, and almost all bacteria were dead as they were stained with strong red fluorescent. The merged images where blue, red and green fluorescent almost fitted together further suggested that compared with previous reports, ${ }^{7 a}$ the treated bacteria were largely accumulated and adsorbed into the $\mathrm{Zn}-\mathrm{CuO} @ \mathrm{GO}$, where their green fluorescent was in good coincidence with bacteria. This phenomenon demonstrated that after integrated with GO sheets, Zn-CuO could effectively cause the accumulation of bacteria onto their recombinant sheet structure to accelerate bacterial lysis.

To elucidate the bacteria-material interactions after treatment, we first tested whether possible antibacterial mechanisms from zeta potential, metal ions and ROS was dominant. Assuming the fact that if zeta potential was dominant in contributing to the antibacterial activities, $\mathrm{Zn}-\mathrm{CuO} @ \mathrm{GO}(\zeta>0$, Fig. S1, ESI $\dagger$ ) should have better activity against Gram-negative MDR E. coli, we careful examined the antibacterial results in Fig. 3 again. The only clue we could detect, however, was that Zn-CuO@GO might be more effective against Gram-positive MRSA (Fig. 3), given that $\mathrm{Zn}-\mathrm{CuO} @ G O(1: 1)$ possessed a better activity towards this strain after 10 min treatment. Such a difference was not detectable for $\mathrm{Zn}-\mathrm{CuO} @ G O(4: 1$ or $2: 1)$, as they could gave a complete inhibition of both strains within $10 \mathrm{~min}$ and exhibited no difference. It was thus indicated that zeta potential might not be a determining factor. Further, we examined the effect from trace amount of metal ion leakage towards bacterial inhibition. As provided in Table S3 (ESI $\dagger$ ), however, the time-lapse release of metal ions in $\mathrm{Zn}-\mathrm{CuO} @ G O$ indicated that, there were minimal leakage of metal ions such as $\mathrm{Cu}^{2+}$ and $\mathrm{Zn}^{2+}$ (only $1.2 \mathrm{mmol} \mathrm{L}^{-1}$ of $\mathrm{Cu}^{2+}$ and
$0.004 \mathrm{mmol} \mathrm{L}{ }^{-1} \mathrm{Zn}^{2+}$ was detected over $3 \mathrm{~h}$ of treatment). The trace amount of $\mathrm{Cu}^{2+}$ and $\mathrm{Zn}^{2+}$ into surrounding environment in turn suggested the leakage of metal ions was hardly a determining factor for $\mathrm{Zn}-\mathrm{CuO} @ \mathrm{GO}$ associated bacterial killing. Additionally, the effects of oxidative stress and ROS production were also tested. For ROS production, a ESR spinning technique was applied, which was effective towards the detection of ROS signals. An important part in ROS generation, $\mathrm{OH}$ radicals $\left({ }^{\circ} \mathrm{OH}\right)$, however, was not detectable here under the actual doses of $0.1 \mathrm{mg} \mathrm{mL}^{-1}$ even upon contact with bacteria. From the ESR curves in Fig. S2, $\uparrow$ the arrow pointed area, which should be indication of the existence of ROS, gave no significant difference even after treatment. To advance our knowledge of possible oxidative stress introduced by $\mathrm{Zn}-\mathrm{CuO} @ \mathrm{GO}$, we also took an in vitro GSH (glutathione) oxidation assay, of which GSH was an antioxidant in bacteria that could prevent damages to cellular components caused by oxidative stress. ${ }^{7 d}$ Through examination of loss of GSH concentration after incubation with $\mathrm{Zn}$ CuO@GO (ESI, Fig. S2 $\dagger$ ), we found that after $2 \mathrm{~h}$ of treatment there were no evident difference in the GSH loss. In fact, loss of GSH was minimal ( $\mathrm{Zn}-\mathrm{CuO} @ \mathrm{GO}(\sim 23.45 \%)$ and $\mathrm{GO}(\sim 21.35 \%))$ in comparison with $\mathrm{H}_{2} \mathrm{O}_{2}(100 \%)$, indicating that $\mathrm{Zn}-\mathrm{CuO} @ \mathrm{GO}$ was not functioning through oxidative stress mechanism. Taken together, we have concrete reasons to believe that $\mathrm{Zn}$ CuO@GO cause severe bacterial lysis differently.

Given its unique nanostructure, we then evaluated physical damage associated antibacterial mechanism, and scanning emission microscope (SEM) was first applied to give detailed elaboration on morphological changes of bacterial after coincubating with $\mathrm{Zn}-\mathrm{CuO} @ \mathrm{GO}$ in saline (Fig. 5). It was found that bacteria without treatment maintained their intact membrane without significant morphological changes (ESI, Fig. S3†). After 30 min extensive contact with $\mathrm{Zn}-\mathrm{CuO} @ G O$, however, it was observed that $\mathrm{Zn}-\mathrm{CuO} @ G O$ nanosheets were attached tightly onto bacterial membrane, which was similar to $\mathrm{Zn}-\mathrm{CuO}$ alone. It was shown in Fig. $5 \mathrm{~A}$ and $\mathrm{B}$, that the bacteria lost their cell membrane integrity, as indicated by their severe
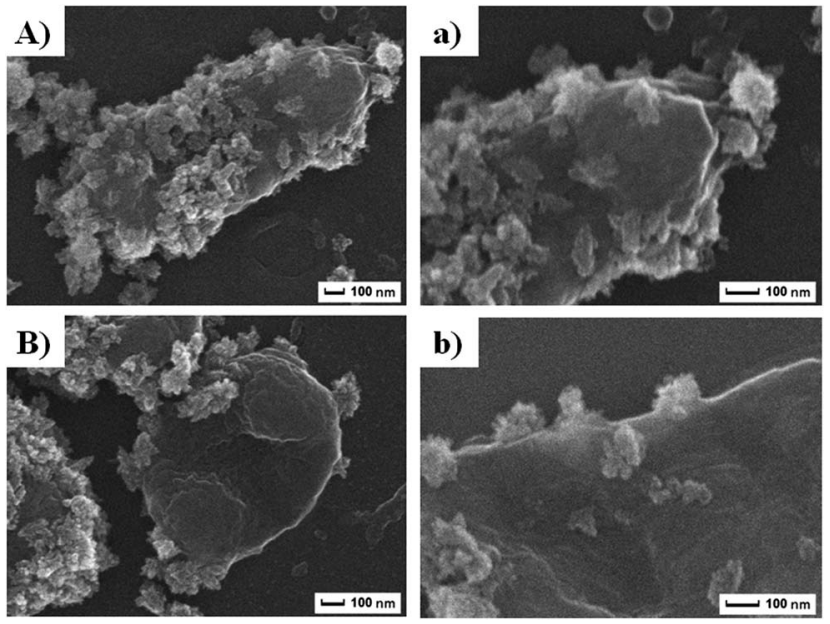

Fig. 5 (A and B) were SEM images of MDR E. coli and MRSA after treatment with $\mathrm{Zn}-\mathrm{CuO}(\mathrm{GOO}$, respectively. ( $\mathrm{a}$ and b) were magnified SEM images revealing detailed cell-material interactions. 
shrinkage, which was especially obvious in Fig. 5B. Notably, ZnCuO@GO may act similarly but in a more effective way taking advantage of $\mathrm{Zn}-\mathrm{CuO}$ and $\mathrm{GO}$ together. Through closer examination of the bacterial surface after treatment, it was found that the surface of $\mathrm{Zn}-\mathrm{CuO}$ treated bacteria was largely corrugated due to their lost of membrane integrity (ESI, Fig. S4 $\dagger$ ), while that from $\mathrm{Zn-CuO@GO}$ treated bacteria was smoother (Fig. 5a and b), which was attributed to the attachment of $\mathrm{Zn}-\mathrm{CuO} @ \mathrm{GO}$ a layered structure that covered the bacterial membrane. As illustrated in Scheme 1(I and II), in linear with prickly $\mathrm{Zn}-\mathrm{CuO}$ NPs alone (I), the deposited Zn-CuO NPs on Zn-CuO@GO nanosheets enable them to effectively anchor into the cell membrane (II), and their delicate nano-pricks could then penetrate into the cell walls from diverse positions, causing the leakage of cytoplasm and subsequent bacteria lysis, which was evidenced by the existence of $\mathrm{Zn}-\mathrm{CuO}$ remaining tightly in the cell wall even after extensive washing (Fig. 5). Synergistically, the layered Zn-CuO@GO could then wrap onto the bacteria surface to deprive of oxygen and nutrient exchange (II), owing to the layered structure of GO nanosheets, which led to a second disastrous inactivation.

To reveal the vivid mechanism of $\mathrm{Zn}-\mathrm{CuO} @ \mathrm{GO}$ towards bacterial-killing as proposed in Scheme 1(II), we investigated their interactions with MDR E. coli and MRSA by TEM. Compared with $\mathrm{Zn}-\mathrm{CuO}$ (ESI, Fig. S5 $\dagger$ ), the red arrow in Fig. 6 indicated the existence of GO sheets which was layer structured and well in combination with prickly $\mathrm{Zn}-\mathrm{CuO}$. As shown in Fig. 6A and $\mathrm{B}$, the $\mathrm{Zn}-\mathrm{CuO} @ \mathrm{GO}$ could bind to bacterial surface extensively due to their strong nonspecific interaction upon contacting, and distributed well throughout the cell wall (corresponding magnified figures were shown in Fig. 6a and b). To make it clearer, we also obtained zoomed figures illustrating the interaction between $\mathrm{Zn}-\mathrm{CuO} @ G O$ and MDR E. coli (Fig. 6), which clearly revealed that $\mathrm{Zn}-\mathrm{CuO} @ \mathrm{GO}$ could then anchor and effectively penetrate into cellular membrane, to cause the cytoplasm leakage (cell lysis) subsequently. Especially, the Zn$\mathrm{CuO} @ \mathrm{GO}$ also form a sublayer wrapping MDR E. coli, as indicated in Fig. 7A. It was also evident in Fig. 7B, that the anchored

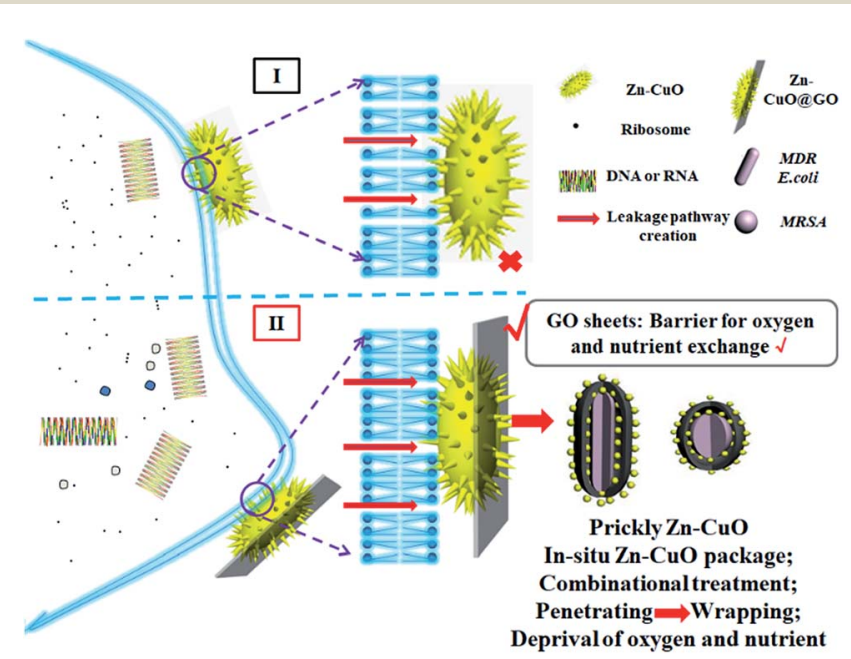

Scheme 1 Schematic illustration of the bacterial killing mechanism of $\mathrm{Zn}-\mathrm{CuO}$ aGO in comparison with prickly $\mathrm{Zn}-\mathrm{CuO}$.
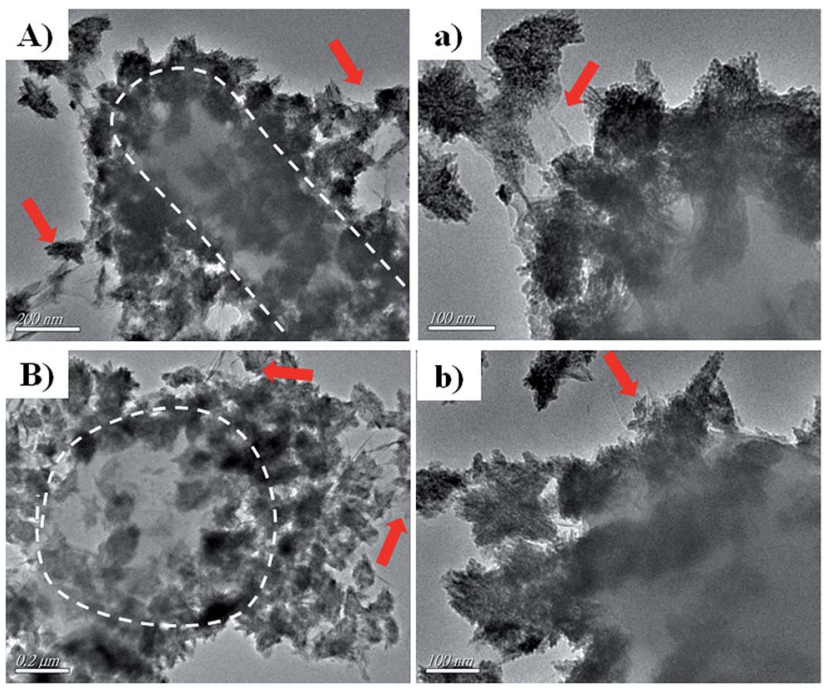

Fig. 6 (A and B) were TEM images of MDR E. coli and MRSA after treatment with $\mathrm{Zn}-\mathrm{CuO}$ (GO, respectively; ( $a$ and b) were their corresponding magnified TEM images, respectively. White dashes outlined the boarders of MDR E. coli and MRSA, and red arrows indicated the existence of $\mathrm{GO}$ as a sublayer for $\mathrm{Zn}-\mathrm{CuO}$ aGO nanosheets.
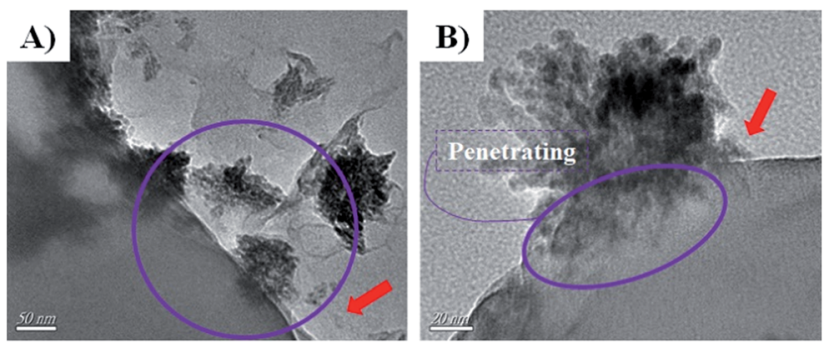

Fig. 7 ( $A$ and $B$ ) were further magnified TEM images uncovering the detailed antibacterial route of $\mathrm{Zn}-\mathrm{CuO}$ aGO in association with MDR E. coli as an example.

$\mathrm{Zn}-\mathrm{CuO}$ could exert their pierce effectively into the cell membrane. To this aspect, we concluded that $\mathrm{Zn}-\mathrm{CuO} @ G O$ could strongly bind to bacterial by wrapping the whole cell wall and dissociate the cell integrity, which also accounted for bacterial accumulation as indicated in Fig. S6 (ESI + ), and verified the results obtained in Fig. 4. Thus, it is believable that the $\mathrm{Zn}$-CuO@GO cause bacterial lysis from stepwise penetrating to wrapping upon contacting, namely, through exerting nanopierce to damage cell walls and subsequently behave to wrap into the cell, which may deprive of oxygen and nutrient exchange and lead to ever-enhanced bacterial inactivation. ${ }^{7 e}$

\section{Conclusions}

In summary, we described a facial, bottom up and environmentfriendly protocol for the scalable fabrication of $\mathrm{Zn}-\mathrm{CuO} @ \mathrm{GO}$ nanocomposite for combinational bacterial-killing, especially towards multi-drug resistant strains, such as MDR E. coli and MRSA. Owing to their combinational antibacterial ability, the Zn-CuO@GO could accelerate bacteria lysis and inactivate 
them nearly completely within 10 min upon contacting. Functioning in a stepwise penetrating and wrapping manner, the deposited prickly $\mathrm{Zn}-\mathrm{CuO}$ in association with GO layer could penetrate and wrap into bacteria membrane to damage bacteria integrity, induce cytoplasm leakage, deprive of possible oxygen/ nutrient exchange, and lead to progressive bacteria lysis. We thus concluded that suspensions containing $\mathrm{Zn}-\mathrm{CuO} @ G O$ nanosheets were promising disinfectant for combating multidrug resistant bacterial stains from ICU to avoid severe bacterial infections.

\section{Conflicts of interest}

There are no conflicts to declare.

\section{Acknowledgements}

The acknowledgements come at the end of an article after the conclusions and before the notes and references.

\section{Notes and references}

1 (a) M. Doidge, A. Allworth, M. Woods, P. Marshall, M. Terry, K. O'brien, H. Goh, N. George, G. Nimmo, M. Schembri and J. Lipman, Infection control and hospital epidemiology, 2010, 31, 418-420; (b) W. Guo, K. Shan, B. Xu and J. Li, Pathog. Global Health, 2015, 109, 184-192; (c) W. Rutala, M. Gergen, E. Sickbert-Bennett, D. Williams and D. Weber, Am. J. Infect. Control, 2014, 42, 426-428; (d) M. Kempf, F. Chen, R. Kern and K. Venkateswaran, Astrobiology, 2005, 5, 391-405; (e) G. Campos, S. Souza, T. Lobão, D. Da Silva, D. Sousa, P. Oliveira, V. Santos, A. Amorim, S. Farias, M. Cruz and R. Yatsuda, New Microbiol., 2012, 35, 183-190.

2 (a) T. Kalaiyarasan, V. Bharti and O. Chaurasiaa, RSC Adv., 2017, 7, 51130-51141; (b) A. Chanda, S. Gupta, M. Vasundhara, S. Joshi, G. Mutta and J. Singh, RSC Adv., 2017, 7, 50527-50536; (c) M. Moritz and M. Geszke-Moritz, Chem. Eng. J., 2013, 228, 596-613; (d) Y. Li, W. Zhang, J. Niu and Y. Chen, ACS Nano, 2012, 6, 5164-5173.

3 (a) X. Xu, Z. Zhang, L. Qiu, J. Zhuang, L. Zhang, H. Wang and Z. Hu, Nat. Nanotechnol., 2016, 11, 930; (b) Y. Tu, M. Lv, P. Xiu, T. Huynh, M. Zhang, M. Castelli and R. Zhou, Nat. Nanotechnol., 2013, 8, 594; (c) C. He, C. Cheng, S. Nie, L. Wang, C. Nie, S. Sun and C. Zhao, J. Mater. Chem. B,
2016, 4, 6143; (d) W. Hu, C. Peng, W. Luo, M. Lv, X. Li, D. Li and C. Fan, ACS Nano, 2010, 4, 4317; (e) F. Perreault, A. De Faria, S. Nejati and M. Elimelech, ACS Nano, 2015, 9, 7226; (f) V. Pham, V. Truong, M. Quinn, S. Notley, Y. Guo, V. Baulin and E. Ivanova, ACS Nano, 2015, 9, 8458.

4 (a) C. Courtney, S. Goodman, J. McDaniel, N. Madinger, A. Chatterjee and P. Nagpal, Nat. Mater., 2016, 15, 529; (b) A. áde Leon, Chem. Commun., 2015, 51, 2886; (c) K. O'Connell, J. Hodgkinson, H. Sore, M. Welch, G. Salmond and D. Spring, Angew. Chem., Int. Ed., 2013, 52, 10706; (d) M. Wu, A. Deokar, J. Liao, P. Shih and Y. Ling, ACS Nano, 2013, 7, 1281; (e) Z. Qi, P. Bharate, C. Lai, B. Ziem, C. Böttcher, A. Schulz and R. Haag, Nano Lett., 2015, 15, 6051; (f) J. Tang, Q. Chen, L. Xu, S. Zhang, L. Feng, L. Cheng and R. Peng, ACS Appl. Mater. Interfaces, 2013, 5, 3867; (g) Y. Zhou, J. Yang, T. He, H. Shi, X. Cheng and Y. Lu, Small, 2013, 9, 3445.

5 (a) B. Atiyeh, M. Costagliola, S. Hayek and S. Dibo, Burns, 2017, 33, 139; (b) W. Jung, H. Koo, K. Kim, S. Shin, S. Kim and Y. Park, Appl. Environ. Microbiol., 2008, 74, 2171; (c) H. Su, S. Lin, J. Wei, I. Pao, S. H. Chiao, C. Huang and J. Lin, PLoS One, 2011, 6, e21125; (d) T. Kavitha, A. Gopalan, K. Lee and S. Park, Carbon, 2012, 50, 2994; (e) E. Zanni, E. Bruni, C. Chandraiahgari, G. De Bellis, M. Santangelo, M. Leone, A. Bregnocchi, P. Mancini, M. Sarto and D. Uccelletti, J. Nanobiotechnol., 2017, 15, 57.

6 (a) R. Wu, Y. Ma, J. Pan, S. Lee, J. Liu, H. Zhu, R. Gu, K. Shea and G. Pan, Biosens. Bioelectron., 2017, 101, 52; (b) E. Malka, I. Perelshtein, A. Lipovsky, Y. Shalom, L. Naparstek, N. Perkas, T. Patick, R. Lubart, Y. Nitzan, E. Banin and A. Gedanken, Small, 2013, 9, 4069; (c) M. Eshed, J. Lellouche, A. Gedanken and E. Banin, Adv. Funct. Mater., 2014, 24, 1382.

7 (a) R. Wu, H. Zhang, J. Pan, H. Zhu, Y. Ma, W. Cui and G. Pan, Adv. Mater. Interfaces, 2016, 3, DOI: 10.1002/admi.201600472; (b) M. Hoop, Y. Shen, X. Chen, F. Mushtaq, L. Iuliano, M. Sakar and S. Pané, Adv. Funct. Mater., 2016, 26, 1063; (c) J. Wang, J. Li, S. Qian, G. Guo, Q. Wang, J. Tang and P. K. Chu, ACS Appl. Mater. Interfaces, 2016, 8, 11162; (d) E. Piskounova, M. Agathocleous, M. Murphy, Z. Hu, S. Huddlestun, Z. Zhao, A. Leitch and T. Johnson, Nature, 2015, 527, 186; (e) C. Nie, C. Cheng, L. Ma, J. Deng and C. Zhao, Langmuir, 2016, 5955. 